\title{
Almaty (Kazakhstan) Youth's Work Values: Sociological Analysis of the Structure and Content
}

\author{
Aidos Bauyrzhanuly Altynbekov ${ }^{1}$ \\ ${ }^{1}$ Al-Farabi Kazakh National University, Almaty, Kazakhstan \\ Correspondence: Aidos Bauyrzhanuly Altynbekov, Al-Farabi Kazakh National University, Al-Farabi Ave., 71, \\ Almaty, 050038, Kazakhstan.
}

Received: December 15, 2014 Accepted: March 10, 2015 Online Published: May 22, 2015

doi:10.5539/ass.v11n14p45

URL: http://dx.doi.org/10.5539/ass.v11n14p45

\begin{abstract}
The results of Almaty youth's work values social research are represented in this article. The impact of such values like high salary, exciting work, position retention guarantee on youth's life and work which became prevailed in youth's professional career path were determined and the factors having impact on them are considered. The question in this article is in young people's opinion concerning risks and opportunities which they meet on their career path, importance of their service quality. Youth's diligence, their work firmness and aspiration are described. Evaluating the view in respect of business activity among young people, considerable opinions about its society advantages are represented. The factors which may form obstacles for young people's direction towards business activity are evaluated according to their importance. The reasons for youth's failure of starting up a new business are mentioned, weaknesses of professional mobility and professional experience are shown. The authors represented beneficial ways for young people stimulation for work, as well as divided them according to youth's opinion. Its predominance on the way towards youth's making progress is analyzed leaning on research results. They tried to determine the correlation between work and money in young people's perception. The author represents his conclusion concerning activities to be made in order to regulate work issues from the very beginning.
\end{abstract}

Keywords: work values, value, youth, young people, business activity, mobility

\section{Introduction}

\subsection{Introduce the Problem}

Different kinds of problems occurring in any society have common focus together with the values in that society. In other words, development or extinction of education, health, family institution, culture, economics, political democratization in the society comes from the system of values which is predominant in the society. For instance, if consumerism in the society, safety need, corruption tolerance, education indifference, anergic values towards family, work, morality are predominant, then regression will prevail over progression in the society. And being predominant of aiming for creative work, family happiness, honest employment, deep knowledge, morality, fairness, politeness, moral values will prevail progression versus regression. Humanity history proved that the young people are those who carried out duties of transferring and renovating these values, handing down from generation to generation. Detailed research of nowadays youth's values will give a chance to prevent possible disadvantages and to describe our future society. Currently, there are a lot of social research results giving an opportunity to understand the youth scientifically. Having relied on such results we can see that the most important of youth's values are family, health care, high financial standing, opportunity of good position. Having represented the hierarchy of work values resulting from the study made within the framework of the dissertation project, in this article we made an effort to seek answers for questions concerning importance of researches showing values for the youth, factors having impact on change of nowadays youth's values, youth's quality of work values. For instance, work values can be mentioned as the basis of employment in the society, business activities, work efficiency, work quality, human's condition and economic prosperity. Currently, it is important to pay attention to the problem of improvement of work quality in parallel with the problem of unemployment. It is easy to find a job for a person. However, the problems of high quality performance of that work are more important than the problems of unemployment. Because, unsatisfactory work (labor) is an obstacle for an institution on its way toward opening of new work places, as well as its development, it deprives the state from 
large-scale tax paying capacity. In other words, even if we say that unemployment and social difficulties have found their solution, regulating (solving) of this problem in a low quality way will generate many other problems in the society. In the very near future, the fact that the basis of medium and small businesses in Almaty (and other regions) will be formed not by the ones who have higher education, but by those who graduated from the secondary specialized colleges, who have secondary-level education will possible. The reason is that the strategy in obtaining higher education is wrong. There is an opinion among most young people and their parents that the person who obtained higher education must work at one work place for a stable salary. For instance, according to the findings of "International Centre of Economic Literacy" Social Fund, 63\% of RK citizens struggle living from paycheck to paycheck ("Capital" Centre of Business Information. Finance, 2014). This information shows that people with higher education try to work in public offices, large and medium-sized companies. Although, the people from the other group, alternatively, work in small businesses, with no intermission and try to earn more money. This problem is a dilemma. On one hand, young people are eager to start their career, on the other hand, young people with higher education do not want to start a business up straight after graduating from the university. This situation may enforce fear and uncertainty to go for business activity as time passes by. Consequently, non-intellectualization of medium and small businesses complicate the course of innovation and modernization. We think that all of the above-mentioned problems are connected to the work values system of nowadays public. Namely, we can say that it seems like if there is no value, there will not be humanity, if there is no satisfactory work value, there will not be reasonable, satisfactory work.

\subsection{Explore Importance of the Problem}

Currently, according to the data of the Committee (Agency) on Statistics of the Republic of Kazakhstan, there are 424853 young people at the ages $16-29$ in the city of Almaty $195174(46 \%)$ males and $229679(54 \%)$ females. (Almaty population by gender and age, 2013). According to national peculiarities Kazakhs $-63.1 \%$, Russians $-24.9 \%$, other nations $-12 \%$ (The youth of the Republic of Kazakhstan. The result of national population census of 2009 in RK). According to The World Factbook 2009, 99.7\% of people older than 15 years old can read and write in Kazakhstan. In other words, $99.8 \%$ of males and $99.7 \%$ of females are literate (Central Intelligence Agency. The World Factbook. Field Listing: Literacy). Up to date, it is a well-known fact that there are many different problems among Kazakhstani youth. Among other things, increasing crime rate among young people can be mentioned. In 2010, Kazakhstan took the third place according to death-rate among the youth in Europe (10.66 deaths per 100000 citizens). Russia took the first place in that ranking, Albania second (Molotov Cocktail. Anatomy of Kazakhstani youth, 2014). Having considered official data, the youth at the ages 14-29 commit $50 \%$ of crimes in our country. For instance, during the primary nine months of the year of 201480803 crimes were committed in our country. Among them, 14-15 years old committed 583 of those, 16-17 years old $2477,18-20$ years old $-8142,21-29$ years old -28936 (of different levels). If these numbers show that the half of these crimes is made by young people, it will be difficult to predict how many of them stay undetermined (Information on age composition of the people committed crimes). Approximately 50000 drug-dependent people are registered officially in Kazakhstan, unofficial data of this quantity of 500000 make us concern of our future (Actual quantity of drug-dependent people in Kazakhstan came near to the mark of half a million people General Prosecutor's Office, 2013). It has been established that the level of suicides is quite high among the youth. Kazakhstan takes one of the top places in the youth suicide level in the world. According to the recent data, the level of suicide among citizens at the ages 15-29 composes 30.8 per 100000 people. For example, the level of suicide among the youth at the age of 5-14 is 3.2 per 100000 people (Preventing suicide. A global imperative. World Health Organization 2014). That is, youth's passage from childhood into adolescence is observed with growth of suicide by 10 times. The issue of health among youth is also important. For example, according to the Bloomberg agency, Kazakhstan ranks No. 111 in Health indicator (Bloomberg Rankings. The world's healthiest countries). In our opinion, there are many reasons of these and other problems, including weakness of youth's labor values and unemployment as the reason of social problems among young people. Let us provide a vivid example which will be an evidence for our words. Currently, it is a well-known fact that there is a war of "Islamic State" terror organization going on in Syria and Iraq and that different radical groups from different places all over the world are affiliating themselves with ISIS (What is Islamic State? BBC News, Middle East, 2014). On 19.11.2014 Nurtay Abykayev the Chairman of the National Security Committee said that 300 Kazakhstanis with the name of "Kazakh community" were carrying on that war in the ranks of "Islamic State" terror organization (Kazakh community. The "Vremya" newspaper, 2014). And at the end of 2012 Johann Merkel the Deputy Prosecutor General of the Republic of Kazakhstan described terrorists' portrait in Kazakhstan on the "Antiterrorism activities in the current situation" conference. Johann Merkel: "Who is Kazakhstani terrorist? Let me answer this question relying on available statistics. Approximately $60 \%$ of terrorists are citizens at the age under 29 years old. In other words, youth representatives. Almost all of them, or more precisely, $95 \%$ 
are unemployed ones. In such a manner, terrorist's portrait of Kazakhstan is youth who is trying to find a niche for themselves, in many instances, unemployed citizens with no education and perspective in future" (The Prosecutor's Office General described the portrait of Kazakhstani terrorist, 2012). We should take into account that if we pay attention to the above mentioned facts, we would see that most of the young people joined extremist (terror) organizations were unemployed young people. In our opinion, if there were great goals and ambitions, values and viewpoints, most of social problems would not occur. If young people had strong work values, they would keep on spiritual struggle without giving a way for defeat. If youth's spare time was organized well, they would not face criminal acts being able to meet competition. Because there is always an opportunity to find any kind of job from any kind of place all over the world for a person who is well-educated and has life force. As this is the problem originated from the weakness of work values and living positions among troubled young people, we consider that it is very important to analyze, evaluate the problem of values among the youth on a permanent basis.

Besides the official data, social research shows that there are different problems among the youth. For example, according to the results of survey conducted by Zhastar Research Center, problems are as follows (Kazakhstan youth - 2013. National report, 2013): There were the following results for "Name the main problems among the youth in your city / town" question put in the survey: 1. Pecuniary burdens (lack of money, high prices) - 13\%; 2 . Difficulty of employment, unemployment $-13 \%$; 3 . Difficulties in obtaining a higher education (high prices) $12.3 \%$; Housing problem $-11.2 \%$; 4. Drug addiction, toxicomania and alcoholism - 7\%; 5. Faithlessness into the future $-5 \%$; 6 . Low level of youth culture, moral insanity $-4.9 \%$; 7. Youthful crime $-4.6 \%$; 8 . Wide expansion of smoking cigarettes by the youth $-4.1 \%$; 9 . No place for recreation $-3.5 \%$; 10 . No chance to obtain a loan easily $-3.2 \% ; 11$. Dissatisfaction in regard of the society, no discipline $-3.1 \% ; 12$. Other reasons (An attempt upon personal security, religious extremism among the youth, no ability to order personal affairs, disputes with parents / representatives of the older generation, poor health conditions, health deterioration, unavailability of high-speed internet connection, cellular communication of high quality) $-14.1 \%$; 13 . There are no problems $-0.6 \% ; 14$. No answer $-0.4 \%$. The results of the social survey show that problems of pecuniary burdens and unemployment are the most important ones. For this reason, there are several reasons to conduct the sociological survey of Almaty young people's work values: 1. The youth are cultural, intellectual and innovational potential of the society; 2. Youth's social, including social adaptation and formation of work values gives an opportunities to determine the attitude towards a certain profession, world-view, philosophy, attitude towards work and labor, to find a right decision; 3. Young people's work value has an impact on their philosophy and life habits; 4. Young people of Almaty city are the young people who are the fastest in adaptation for new conditions among all the social groups. Accordingly, there is an issue to be mentioned that youth who are "cutting teeth in a life journey" are the first ones who come under the influence of transition period. Furthermore, the study of Almaty young people's value directions offers an opportunity to determine the work values of the entire young people population.

\subsection{Describe Relevant Scholarship}

Ronald Inglehart is the person who conducts researches of the values in the world in a practical manner on a permanent basis. Since 1970 R. Inglehart has been developing the theory of post-modernism. His scientific point of view has been based on the results of the research "World value survey" which is conducted on all the continents of the world since 1976. In his opinion, the publics of the Western countries could be developed only under the conditions of acceptance of individual values and transformation from material values into post-material values. That is to say, he writes that human owning economic, physical security values will be developed only if they will be changed into the values directed for independent and personal development (Inglehart, R. Changing Values among Western Publics from 1970 to 2006). Consequently, the answer for the question "Will the state be developed in the conditions of forming of independent values or due to forming of political system in the modern world?" is searched. Relying on the result of researches conducted by Inglehart throughout many years, he makes a conclusion that the state will be developed forming personal values in the society. For instance, nowadays nobody believes (many people do not believe) that proletariat revolution can stop exploitation and collisions through liquidation of private property. Industrialization will not lead automatically to democracy, because fascism and communism also occurred through industrialization. None the less, he says that economic development will bring changes in the society, culture and politics. Economic development, each stage of industrialization and modernization development will lead to changes in people's world view. Industrialization establishes conditions for bureaucratization, hierarchization and centralization and secularization of governance, as well as transformation from traditional values into extremely rational values. And post-industrial society provides predomination not for bureaucratization and centralization, but for 
self-dependence and self-development of a separate person which will lead to emancipation from governance. Consequently, people will become more patient and will trust others during economic development. R. Inglehart writes that history of the country fulfills an important role in the social and economic changes of the public. Hence, he also writes that economic development has an impact on the world view formed through the heritage developed with the help of Protestantism, Catholicism, Islam, Confucianism and Communism. For instance, there are lots of Muslim countries, however, the level of economic development, education and culture is different in Malaysia and Pakistan, Kazakhstan and Afghanistan, Uzbekistan and Iraq, Indonesia and Syria, United Arab Emirates and Algeria. In a word, economic development assists to perceive in different ways the attitude towards the different issues in the society and person's growth of education. Requirements and demand of civilized people with great economic status is rather high. R. Inglehart's opinion in analyzing, interpretation of our investigations. Because, material values prevail comparing to self-dependent values in Kazakhstani society, and the fact that in the near future transformation from material values into self-dependent values will lead to what kind of changes gives an opportunity to explain mechanisms of possible scenarios in the society.

\section{Method}

This article is based on the results of the author's sociological survey conducted in the seventh district of Almaty city in the period from January to April of 2014. The objective of this article is to specify young people's work values directions by means of the quantitative investigation methods, search of strengths and weaknesses, analysis of opportunities and dangers. The investigation object is the youth at the ages between 16 and 29. The law of youth policy of our present-day country determines the youth as the citizen of the Republic of Kazakhstan at the age between 16 and 29 (The Law of youth policy in the Republic of Kazakhstan No. 584 of the Republic of Kazakhstan, 2004). This age interval is confirmed in the most countries all over the world. Nevertheless, we have considered the young people at the ages 16 to 29 years old in our investigation. Its main reason is 1 paragraph of 30 article of the Labor Code of the Republic of Kazakhstan (Code of the Republic of Kazakhstan, 2007) stating that a person over 16 years old is entitled to sign an employment agreement. In other words, allowance for work is granted for people over 16 years old (restrictions may apply). The other reason is the fact that 16 years old is the period when school graduates choose their professions and college students are set to study the profession that they've chosen. The third reason, economically active age starts from 16 years old.

Selection capacity is 500 respondents. Quantitative method of the research is used in order to achieve research objective. The method of quantitative research data collection: personal standard interview. Selection represents the young people of the seventh district of Almaty city in the specified age category. Statistical error does not exceed $\pm 3.1 \%$ at the confidence interval of $95 \%$. Investigation data were analyzed using SPSS 17.0 computer program.

Desk research or traditional documentary research. The analysis of additional information sources was conducted within the framework of the above-mentioned method. Used documents can be divided into the following groups:

(a) Statistical collection and other information of statistical character. The main source of this information is publications on the official web-site www.stat.gov.kz of the Statistics Committee, Ministry of National Economics, the Republic of Kazakhstan (Ministry of National Economics of the Republic of Kazakhstan, Committee on Statistics. www.stat.gov.kz). Such selection of related articles like "demography", "youth", "work" were used;

(b) Kazakhstani sociological organizations and research results of separate investigators. Investigations of "Zhastar" research center were used in the article preparation ("Zhastar" research center. http://youthpolicycenter.kz/ru/institucionalnaya-podsistema/nic-molodezh.html);

(c) The investigation and scientific works database of the Institute of Education Sciences - The Education Resources Information Center (ERIC) were evaluated (Institute of Education Sciences - The Education Resources Information Center (ERIC) http://eric.ed.gov/).

\section{Results}

The main part of our investigation is directed to determine the hierarchy of the youth's work values. Respondents were asked the question "What is important for you in your career path (at your work), evaluate?". The results of obtained answers on this question are provided in the first table.

According to the information provided in the table, "high salary" position ranks No. one for the young people among the work values. The second important value for the youth is "exciting work". The fact that the value of "having an exciting and highly-paid job" is the most important values was determined in the part directed in the 
life values of our investigation. The result of the questions dedicated to determine the hierarchy of the youth's work values shows that specified values are above the other work values. "Guarantee of position retention" is the third main value for the young people. Paying attention to the most analyses, represents that values may be generated from the need. For example, we can associate the matter that the value of high salary prevails among the other work values for the modern youth with several factors. Firstly, the most of the respondents are dependent on the salary, secondly it shows that the young people face pecuniary burdens in the life start, thirdly, Almaty youth are not only local ones, and also they consist of the young people who came here to study and stayed here after graduation and who is seeking for the job from other regions. However, structure of the youth is complex, their demands are different. Exciting work for the youth is nowadays in demand. We can expect from this tendency that work's productivity and efficiency will increase, if the young people do their work with a great interest. To achieve "the results of work" is very valuable for the respondents. "Exciting work" and "to achieve the results of work" are the most needed demands of current labor market.

Table 1. Youth's work values

\begin{tabular}{|c|c|c|c|}
\hline \multirow{2}{*}{$\begin{array}{l}\text { What is important for you in your career path (at your work), evaluate? } \mathrm{N}=500 \\
\qquad(2416)\end{array}$} & \multicolumn{2}{|c|}{ Answers } & \multirow{2}{*}{$\begin{array}{c}\text { Control } \\
\text { percentage }\end{array}$} \\
\hline & $\mathrm{N}$ & Percentage & \\
\hline High salary & 237 & $9.8 \%$ & $47.4 \%$ \\
\hline Exciting work & 224 & $9.3 \%$ & $44.8 \%$ \\
\hline Guarantee of position retention & 185 & $7.7 \%$ & $37.0 \%$ \\
\hline To see the results of work & 184 & $7.6 \%$ & $36.8 \%$ \\
\hline Healthy relationships with colleagues at work & 168 & $7.0 \%$ & $33.6 \%$ \\
\hline Good opportunities of career development & 155 & $6.4 \%$ & $31.0 \%$ \\
\hline Presence of opportunities of personal and professional development & 150 & $6.2 \%$ & $30.0 \%$ \\
\hline Work's profitability for the society & 137 & $5.7 \%$ & $27.4 \%$ \\
\hline Comfortable work atmosphere, provision with necessary equipment and hi-tech & 131 & $5.4 \%$ & $26.2 \%$ \\
\hline Opportunity to work separately, independently & 114 & $4.7 \%$ & $22.8 \%$ \\
\hline Availability of material essentialities & 111 & $4.6 \%$ & $22.2 \%$ \\
\hline Opportunity to help other people & 95 & $3.9 \%$ & $19.0 \%$ \\
\hline Flexible work schedule & 91 & $3.8 \%$ & $18.2 \%$ \\
\hline Direction's fair attitude towards personnel & 83 & $3.4 \%$ & $16.6 \%$ \\
\hline Self-security and security of relatives & 81 & $3.4 \%$ & $16.2 \%$ \\
\hline Public's recognition of the labor & 60 & $2.5 \%$ & $12.0 \%$ \\
\hline Availability of artistic license & 52 & $2.2 \%$ & $10.4 \%$ \\
\hline Easiness and good earnings & 48 & $2.0 \%$ & $9.6 \%$ \\
\hline Consideration of social aids & 36 & $1.5 \%$ & $7.2 \%$ \\
\hline A lot of days-off & 31 & $1.3 \%$ & $6.2 \%$ \\
\hline Opportunity to use employment-related powers & 28 & $1.2 \%$ & $5.6 \%$ \\
\hline Opportunity to take a bribe & 15 & $0.6 \%$ & $3.0 \%$ \\
\hline Total & 2416 & $100.0 \%$ & $483.2 \%$ \\
\hline
\end{tabular}

There are such values like "easiness and good earnings of work", "consideration of social aids", "a lot of days-off", "opportunity to use employment-related powers", "opportunity to take a bribe" are the least of the youth's work values list. If we pay attention to the research results, we can say that the modern youth understand that it is not easy to achieve good earnings. Easy work will never be a key for good earnings. $1.5 \%$ chose "consideration of social aids" answer. Our understanding is that this indicator may be given two reasons. On one hand, lowering of paternalistic values in the youth's nature. On the other hand, deficiency (lack) of social aids for the youth nowadays. Social aids (social packages) are very important for many people. However, in the case when the social aids are very low, people want to compensate them with high salary. Currently, there are many days-off in our country, there is such opinion that our people prefer to go on holiday. Existence of holidays in our countries is at medium level comparing to the holidays in other countries. And presence of numerous days-off is not so much important for the youth. Investigation results show that many young people are ready to work on days-off.

Social academics' opinion is significant in understanding the specified information. In 1978, Feldman and Arnold research determines that such values like high salary (earnings), self-development, competence, self-dependence, independence, responsibility and flexible work schedule plays significant role in people's work selection. They believe that great predominance of salary importance may serve as obstacles in the way of 
development of important personal qualities (Feldman \& Arnold, 1978). And S. Zedeck (1977) writes that potentials of personal development are possible in the conditions of high salary and work flexibility (Zedeck, 1977). And so, pecuniary burdens and problem of creative work possibility must be regulated for the purposes of personal development. S. Rynes, D. Schwab and H. Heneman (1983) write that each person has work requirements which satisfies him and which he needs. For instance, the youth who are just starting their career path may be satisfied with medium level salary (Rynes, Schwab, \& Heneman, 1983). It is true that the youth are ready to work with medium salary in spite of the matter that they desire a high salary in our situation. However, S. Rynes supports the possibility that organization will not have benefit from the lack of one of person's work values salary.

We aimed to determine the youth's indicator of taking the risk with the help of the question "What conditions would you choose, if you had a right to choose?" ( $\mathrm{N}=500)$. In concordance with the results, 39.4\% of respondents chose the answer "security and stability of work, but limitation of career, creative progress", and $31.6 \%$ of respondents chose "high level of creative and professional progress, but uncertainty and danger of work" answer. In comparison, most of the youth desire their work to be secure and stable. In other words, these results also clarify the importance of "guarantee of position retention" value. We cannot say it is a low indicator that $31.6 \%$ of the young people are ready to take the risks for creative and professional progress. This indicator shows that there are the young people who are ready to take the risks. Existence of the youth who are ready to take the risks strengthen the possibility of strong changes. $29.0 \%$ of all the respondents are in the range of giving "no answer". These young people are among those who seek for a secure, stable job position with opportunities of career and creative progress. The youth of this group seem to be close to "security and stability of work, but limitation of career, creative progress". Because we have written that there are a lot of young people who desire "guarantee of position retention" in the primary questions. It is well-known that people will take the risks with difficulty, if they face challenges. This group needs stable social and economic situation in the state and their lives in order to take the risks.

Table 2. Youth's work motivation

\begin{tabular}{lccc}
\hline What are the most important methods of people motivation for work? N=495 & Frequency & Percentage & Valid percentage \\
\hline Wage increase & 127 & 25.4 & 25.7 \\
Management's appreciation of the service & 118 & 23.6 & 23.8 \\
Career promotion & 107 & 21.4 & 21.6 \\
Assistance in obtaining the housing & 65 & 13.0 & 13.1 \\
Opportunity of knowledge advance & 55 & 11.0 & 11.1 \\
Availability of social aids & 23 & 4.6 & 4.6 \\
Total & 495 & 99.0 & 100.0 \\
\hline
\end{tabular}

Currently, there are many methods of people motivation mentioned. Remunerative incentives, creation of conditions for knowledge advance, appreciation of service are common motivators for everybody. "Wage increase", "management's appreciation of the service", "career promotion" were clarified in out investigations as the motivators for youth's work stimulation. The method of stimulation "assistance in obtaining the housing" is very important for Almaty young people. "Availability of social aids" covers a very small part of stimulation (4.6\%). We can notice that "availability of social aids" does not prevail in the youth's consciousness for modern young people. We can suppose that the reason is that social aids (social packages) are not so high for today. We consider there is a belief among the young people that it is possible to achieve with the help of high salary, good position, not with the help of the aids. The investigation result shows that "opportunity of knowledge advance" does not stimulate young people at a high level. This fact can still be considered as a holdback for transmission of our public into "smart economics". The problem is not only in the youth, it lays in the system of youth motivation. For example, at the present a person's salary does not depend on his/her proper work in most of organization. An employee working properly and an employee working improperly gets equal salary. Correspondingly, people desire only high salary. And if the salary was dependent on their work results, the contribution an employee made in order to develop the organization, such values like work results, qualification, knowledge would be predominant among people.

We surveyed respondents on "Life achievements can be reached with work only, do you agree with this opinion?" matter $(\mathrm{N}=500)$. The significant part of the young people answered that life achievement can be reached with "work" only (69.6\%). "Hesitate to answer" was $17.0 \%$, "do not agree" - 10.2\%, "no answer" was $3.2 \%$. These numbers show that modern youth soaked up the values of capitalism (post-modernism) and understands the role of work in their lives. 
We tried to determine youth's agreement (disagreement) for the question "Stable medium salary is better than unstable salary" $(\mathrm{N}=500)$. Investigation result determined that the young people prefer "stable medium salary rather than unstable high salary". In other words, $50.6 \%$ preferred "medium salary". And $24.6 \%$ of respondents answered that they hesitate, $22.2 \%$ answered that they "do not agree". Those who gave "no answer" were $2.6 \%$. Exactly half young people consider that "medium salary is better than unstable high salary" nowadays. The mentioned tendency can be connected to several factors:

- Youth's preference of stable medium salary rather than unstable high salary is connected to work unsteadiness;

- Youth's striving to government-owned agencies is connected to the fact that government salaries are stable;

- Existence of such opinion among the young people like "Will I be able to find a new job, if I lose my current job position?"

- Dependence and low level of self-confidence among the young people.

We asked respondents their opinion on the statement "I would find a new job easily, if I lose my current job position" $(\mathrm{N}=500)$. The results of answers:

$$
\begin{aligned}
& \text { - Agree }-30.0 \% \text {; } \\
& \text { - Do not agree }-37.0 \% \text {; }
\end{aligned}
$$

- Hesitate - 27.0\%;

- No answer $-6.0 \%$.

We can see that $30.0 \%$ of the answers were "I would find easily, if I search" respondents gave for the survey "I would find a new job easily, if I lose my current job position". Two-thirds of the young people hesitate. In other words, it is unknown if I can find a job or not. $37.0 \%$ of respondents said "I will not find a job, if I search for it now". In our opinion, several statements can be made for the mentioned indicators:

- This fact shows that there is a problem of finding or not finding a job among one part of the young people.

- In other words, youth's level of professional mobility is low. Low level of professional mobility forms fear and fluctuation of getting an employment, change of employment;

- We consider that it is important to take into account that there are pupils and students among those who gave an answer "I cannot find a job";

- We believe that "I will find a job easily, if I lose my current position" statement completes "stable medium salary is better than unstable high salary" question.

The results of "If I were rich, I would not work" question for the respondents $(\mathrm{N}=500)$ were as follows:

$$
\begin{aligned}
& \text { - } \quad \text { Agree }-18.4 \% \text {; } \\
& \text { - Do not agree }-64.0 \% \text {; }
\end{aligned}
$$

- Hesitate $-16.0 \%$;

- No answer $-1.6 \%$.

It is a well-known fact that progress in any society is connected to existence of rich people and scientists. The survey was conducted in order to determine the young people's thoughts if they would or would not work, if they were rich. Those who gave "If I were rich, I would not work" answer were $18.4 \%$. In other words, if this group was rich, the work on increase their wealth, improve their job would decelerate. Because the main goal of this group is not to grow rich through improvement of their job, but improvement of their job in order to grow rich. If they became rich, their work would not likely be significant, as though it was if they were in need of material requirements. The proportion of the group that is between this group and the group wishing to work, even if they were rich (hesitating) is $16.0 \%$. This group's thinking border is between these two thoughts. Choosing the appropriate answer likely depends on political and economic situations in the country. The proportion of respondents who answered that they would work, even if they were rich is $64.0 \%$. The goal of this group is to grow rich in order to improve their job. That is to say, there is a base of people who establish a goal to develop further their professional skills, achieve bigger accomplishments in their lives, even if they were rich. A big quantity of people desiring to work in spite of their healthy financial standing is important for our society to develop as we go forward. For instance, it is known that since 1960 South Korea started to progress turning toward economic freedom. In 1985, the scientist named Kim Kyong-Dong conducted a survey research concerning "Would you work, if you had enough money to live well?" question among South Korea workers. As a consequence, $96 \%$ of respondents said "we will keep on working". Meanwhile, we can notice that work is not an instrument to stay alive only, but also to show their worth and achieve high goals for Korea people (Kim, Kyong-Dong. Man and Society in Korea's Economic Growth (Seoul: Seoul National University Press, 1985). Certainly, this is the statistics conducted among the entire workers of South Korea. We want to show that there is an opportunity for progress the same way as specified country, if there was no situation when work is just an instrument of making money in the society with the help of the pointed example. 
It is well-known that the one of the basic driving forces is workers in any society. Society's direction towards business activities is the factor giving an impulse to society progress. In this regards, we have asked a few questions young people in order to recognize respondents' values and convictions concerning business activities. The results of answers respondents gave to "What is your attitude towards the businessmen?" are provided in the Table 3.

Table 3. Youth's attitude towards business activities

\begin{tabular}{lccc}
\hline \multicolumn{1}{c}{ What is your attitude towards the businessmen? N=491 } & Frequency & Percentage & Valid percentage \\
\hline They are economics' drive forces & 196 & 39.2 & 39.9 \\
They provide with work places & 149 & 29.8 & 30.3 \\
They think of their own profit only & 125 & 25.0 & 25.5 \\
They do not generate any value for the society & 21 & 4.2 & 4.3 \\
Total & 491 & 98.2 & 100.0 \\
\hline
\end{tabular}

The majority of respondents of "What is your attitude towards the business activities?" survey consider businessmen as economics' driving force. One third of respondents believe that they provide with work places, one fourth considers that they think of their own profit only, and the rest believe businessmen generate no value for the society. According to the information provided in the table, $1 / 3$ of the young people think negatively of businessmen. We wrote in our scientific analyses that there a greater preference of businessmen rather than public officers in the society in countries development. We believe that currently a man of action must be an ideal person for our society. Because a businessman is a citizen who generates value for our society, knows his stuff, pays taxes to the government, generates revenue, provides people with work places. Business activity is the start of innovation and modernization. It is a well-known fact that in the case if $80 \%$ of any citizens conduct small and medium businesses, the state will advance up to a point. That is why, currently we suppose that promotion of fair labor, business activities, setting an example of fair business activities is a very important problem.

The following question put to respondents targeted to determine youth's desire to "Go into my own business and work on it" $(\mathrm{N}=500)$. The results of the survey were as follows:
- $\quad$ Support $-70.0 \%$;
- I would use such an opportunity $-18.6 \%$;
- Do not support $-8.4 \%$;
- No answer $-3.0 \%$.

We can see that there are a lot of young people desiring to "go into my own business and work on it". 1/5 part of the youth said that they would use "an opportunity to carry on business". And 1/10 part of the young people do not want to "carry on business". This investigation shows that the youth desires to carry on business and they would go into their own business, if they had an opportunity. In order to learn deeper this information, we asked the youth what are the obstacles in setting up a business in their opinion. The investigation results are provided in the Table 4.

Table 4. Youth's business activities

\begin{tabular}{|c|c|c|c|}
\hline \multirow{2}{*}{$\begin{array}{l}\text { What are the obstacles in setting up a business? } \\
\qquad \mathrm{N}=487(827)\end{array}$} & \multicolumn{2}{|c|}{ Answers } & \multirow{2}{*}{ Control percentage } \\
\hline & $\mathrm{N}$ & Percentage & \\
\hline Lack of funds & 302 & $36.5 \%$ & $62.0 \%$ \\
\hline Fear to set up a business & 133 & $16.1 \%$ & $27.3 \%$ \\
\hline Lack of abilities & 79 & $9.6 \%$ & $16.2 \%$ \\
\hline Corruption & 69 & $8.3 \%$ & $14.2 \%$ \\
\hline Bureaucratism & 67 & $8.1 \%$ & $13.8 \%$ \\
\hline Lack of business connections & 63 & $7.6 \%$ & $12.9 \%$ \\
\hline I do now want to go into a business & 60 & $7.3 \%$ & $12.3 \%$ \\
\hline No answer & 28 & $3.4 \%$ & $5.7 \%$ \\
\hline I have my business & 26 & $3.1 \%$ & $5.3 \%$ \\
\hline Total & 827 & $100.0 \%$ & $169.8 \%$ \\
\hline
\end{tabular}

A significant part of respondents named the problem of money lack as the main reason of "What are the obstacles in setting up a business?" question. According to respondents" answers "fear" and "lack of abilities" are the the second and the third problems. The young people named "corruption" and "bureaucratism" as one of the main problems in setting up a new business. Some youth consider "lack of business connections" as an obstacle in setting up a business. $7.3 \%$ of respondents think that "they do not want to go into a business" and 3.1\% of respondents have their own business. According to research conclusion, the reasons forming obstacles for setting up new businesses may be divided into two groups. 
First group:

- Lack of funds;

- Fear;

- Lack of abilities.

\section{Second group:}

- Corruption;

- Bureaucratism;

- Lack of business connections.

We cannot say that the problems in the second group generally are the absolute obstacles in setting up a new business. We think that these are the reasons which may form obstacles for existing business development. But, we believe that they cannot be the main reason of setting up a new business. Currently, neither acquainatces, nor documents, nor corruption may obstruct for any person who has striving and real eagerness in our country.

The reasons in the first group are very complicated and connected to the problem of personal quality. Lack of funds is the problem which is faced by any person, a businessman setting a new business. This problem can be solved on the part of the government with the help of credit projects taking into account the businessman's capabilities. In other words, this is the system-related problem which may be solved through "public and private" entrepreneurial partnership. The thing that stops and brakes a person who is setting up any business is "fear and uncertainty" (lack of abilities). Regulation of this problem stems from education providing to today children, labor implanting, the values learnt and soaking up to our children. And we think that modern youth's uncertainty was originated from lack of work experience, low professional mobility and insufficiency of employment training.

\section{Conclusion}

During the analysis of investigation results conducted among Almaty youth, the following tendencies can be emphasized concerning youth's work values:

- Material values prevail in the young people's consciousness rather than self-development (self-dependent) values;

- The indicators of such negative values like "taking a bribe", "appropriation of corporate opportunities", "easy and well-paid work" is low in the youth consciousness among young people's work values;

- Pursuance of both business activities and civil services is rather high among the youth. Establishment on civil services is connected to a stable salary, guaranteed work place and administrative resources. And the main obstacles of young people's setting up a new business are associated with such personal qualities like "lack of funds", "fear" and "lack of abilities".

- The majority of the youth who prefer a stable medium salary rather than an unstable high salary is noticed among the young people. In other words, some youth show assurance instability of the current labor market, and some other young people doubt the strength of their own personal qualities.

Analyzing the above-mentioned tendencies, the young people can be divided into the following groups:

- The group aiming to obtain well-paid job (with high salary) through professional progress;

- The group motivated to achieve high earnings using minimal resources (parents help, acquaintances' resources);

- The group motivated to work at the stable work place with stable earnings (salary);

- The group directed to set up their own business, to carry on business under all circumstances.

We have represented the hierarchy and preferences of current Almaty (Kazakhstan) youth's work values in our article. We have analyzed the main problems and perspectives. In our opinion, material values are more important rather than self-dependent values for the current youth. For instance, there are "salary-career-professional progress" values in the hierarchy of the youth's work values. Theoretically this hierarchy should look like "professional progress-career-salary" values. The formula is explained by R. Ingelhart's theory. It shows that democratic changes in the society and industrial transformation are ahead.

\section{References}

“Youth" Research Center. (n. d.). Retrieved February 18, 2014, from http://youthpolicycenter.kz/ru/institucion alnaya-podsistema/nic-molodezh.html.

$63 \%$ of Kazakhstanis struggle from paycheck to paycheck. (2014, April 15). "Capital" Center of business information. Finance. Retrieved February 18, 2014, from http://kapital.kz/finance/28979/63-kazahstancevzhivut-ot-zarplaty-do-zarplaty.html.

Actual quantity of drug-dependent people in Kazakhstan came near to the mark of half a million people- 
General Prosecutor's Office. (2013, June 3). Retrieved February 18, 2014, from http://www.inform.kz/rus/ article/2563199

Almaty population by gender and age in 2012. Demography (14th ed.). (n. d.). Agency of Statistics of the Republic of Kazakhstan. Department of Statistics of Almaty.

Bloomberg Rankings. (n. d.). The world's healthiest countries. Retrieved February 18, 2014, from http://images.businessweek.com/bloomberg/pdfs/WORLDS_HEALTHIEST_COUNTRIES.pdf

Bokanova, Zh., Karimova, Zh., Ilyassova, G., Massatova, B., Khamichev, K., Varkentin, Ye., Kudaibergenov, R., \& Abrayeva, R. (2013). Kazakhstani youth - 2013. National Report. Astana: "Zhastar" Research Center.

Central Intelligence Agency. (n. d.). The World Factbook. Field Listing: Literacy. Retrieved February 18, 2014, from https://www.cia.gov/library/publications/the-world-factbook/fields/2103.html\#136.

Data on age composition of people committed crimes. (n. d.). Committee for Legal Statistics and Special Accountings of the General Prosecutor's Office of the Republic of Kazakhstan. Retrieved February 18, 2014, from http://pravstat.prokuror.kz/rus.

Feldman, D., \& Arnold, H. (1978). Position choice: Comparing the importance of organizational and job factors. Journal of Applied Psychology, 63, 706-710. http://dx.doi.org/10.1037/0021-9010.63.6.706

General Prosecutor's Office described the portrait of Kazakhstani terrorist. (2012, November 22). Retrieved February 18, 2014, from http://www.zakon.kz/4526127-genprokuratura-opisala-portret.html.

Inglehart, R. (n. d.). Changing Values among Western Publics from 1970 to 2006. West European Politics, $31(1-2), 130-46$.

Institute of Education Sciences - The Education Resources Information Center (ERIC). (n. d.). Retrieved February 18, 2014, from http://eric.ed.gov/

Kazakh community. (2014, November 19). The "Vremya" newspaper. Retrieved February 18, 2014, from http://knb.kz/ru/archive/article.htm?id=10383557@egNews

Kim, K. (1985). Man and Society in Korea's Economic Growth. Seoul: Seoul National University Press.

Ministry of National Economics of the Republic of Kazakhstan. (n. d.). Committee on Statistics. Retrieved February 18, 2014, from http://www.stat.gov.kz

Molotov Cocktail. Anatomy of Kazakhstani youth. (2014). Almaty: Alliance of Analytics Organizations, Fund named after Konrad Adenauer.

Preventing suicide. A global imperative. World Health Organization. (2014). Retrieved February 18, 2014, from http://apps.who.int/iris/bitstream/10665/131056/1/9789241564779_eng.pdf?ua=1\&ua=1

Rynes, S., Schwab, D., \& Heneman, H. (1983). The role of pay and market pay variability in job application decisions. Organizational Behavior and Human Performance, 31, 353-364. http://dx.doi.org/10.1016/00305073(83)90130-7

The Code of the Republic of Kazakhstan No. 251. (2007, May 15). The Labor Code of the Republic of Kazakhstan. Retrieved from https://www.enbek.kz/ru/normativno-pravovye-akty-v-sfere-zanjatosti/trudovoj -kodeks-respubliki-kazahstan.

The Law of youth policy in the Republic of Kazakhstan No. 584 of the Republic of Kazakhstan. (2004, July 7). Retrieved February 18, 2014, from http://adilet.zan.kz/kaz/docs/Z040000581_.

The youth of the Republic of Kazakhstan. The result of national population census of 2009 in the Republic of Kazakhstan (2010). Agency on Statistics of the Republic of Kazakhstan.

What is Islamic State? BBC News, Middle East. (2014, September 26). Retrieved February 18, 2014, from http://www.bbc.com/news/world-middle-east-29052144

Zedeck, S. (1977). An information processing model and approach to the study of motivation. Organizational Behavior and Human Performance, 18, 47-77. http://dx.doi.org/10.1016/0030-5073(77)90018-6

\section{Copyrights}

Copyright for this article is retained by the author(s), with first publication rights granted to the journal.

This is an open-access article distributed under the terms and conditions of the Creative Commons Attribution license (http://creativecommons.org/licenses/by/3.0/). 